\title{
STRATEGI PEMASARAN CENGKEH (SYZYGIUM AROMATICUM) DI DESA LANGDA KECAMATAN BUNTU BATU, KABUPATEN ENREKANG
}

\author{
Irmayani, Kusnady Tabsir, dan Mustawakkal \\ Program Studi Agribisnis \\ Fakultas Pertanian, Peternakan dan Perikanan \\ Universitas Muhammadiyah Parepare \\ E-mail : mustawakkal16@gmail.com
}

\begin{abstract}
ABSTRAK
Penelitian ini dilaksanakan di Desa Langda Kecamatan Buntu Batu Kabupaten Enrekang pada bulan Maret sampai April 2020. Penelitian ini bertujuan untuk mengetahui faktor internal dan eksternal yang memengaruhi pemasaran cengkeh serta menentukan strategi pemasaran cengkeh yang memungkinkan untuk diterapkan dalam pemasaran cengkeh petani Desa Langda Kecamatan Buntu Batu Kabupaten Enrekang. Metode yang digunakan adalah analisis SWOT untuk mengetahui kekuatan, kelemahan, peluang dan ancaman kegiatan usahatani budidaya cengkeh. Berdasarkan analisis faktor internal ditemukan bahwa kekuatan memliki skor 2.03 lebih tinggi dibandingkan kelemahan yang hanya memiliki skor 0.51 , sedangkan pada faktor eksternal peluang memiliki skor 1.89 lebih tinggi dari ancaman yang hanya memiliki skor 0.58. Posisi internal cukup kuat dalam memanfaatkan kekuatan untuk mengatasi kelemahan. Strategi SO merupakan strategi yang menggunakan kekuatan untuk memanfaatkan peluang dalam peningkatan produksi guna mendapatkan keuntungan yang optimal.
\end{abstract}

Kata kunci: Analisis SWOT, Cengkeh, Strategi Pemasaran

\section{ABSTRACT}

This research was conducted in Langda Village, Enrekang Regency from March to April 2020. The objective of this study is to determine the internal and external factors that affect clove marketing and determine the clove marketing strategy that can be applied to the clove farmers in Langda Village, Buntu Batu Sub-Regency, Enrekang Regency. The method used is SWOT analysis which determine the strengths, weaknesses, opportunities and threats of clove farming activities. Based on the analysis of internal factors, it was found that strengths have a score of 2.03 meanwhile weaknesses have a score of 0.51. In the external factors, opportunity have a score of 1.89 and threats have only a score of 0.58. Internal position is strong enough to use strength to overcome weakness. SO strategy is the strategy that uses strength to take advantage of the opportunities in increasing production in order to get optimal profit.

Keywords: SWOT analysis, cloves, marketing strategy 


\section{PENDAHULUAN}

Cengkeh memegang peranan penting dalam pembangunan perkebunan khususnya dan pembangunan nasional pada umumnya (Nur Djanna, 2007). Cengkeh sebagai bahan baku rokok kretek, obat-obatan dan kebutuhan industri makanan, tidak bisa dipungkiri memiliki peran besar dalam perekonomian nasional seperti lahan kerja, peningkatan devisa negara, peningkatan pendapatan bagi para petani dan kegiatan lainnya yang bersentuhan dengan komoditi cengkeh.

Pada tingkat nasional cengkeh memiliki kondisi pasang surut yang disebabkan oleh besarnya fluktuasi harga cengkeh, biaya panen dan tingginya biaya pengolahan, sedangkan tanaman cengkeh memiliki karakteristik yang khas yaitu panen besar kemudian panen kecil di tahun berikutnya dan pada periode tertentu panen (Siregar, 2011). Panen raya atau panen besar biasanya harga turun yang mengakibatakan petani rugi karena tingginya biaya operasional. Hal ini memengaruhi semangat para petani untuk memelihara tanamannya dan berfikir untuk beralih kekomoditi lain yang dianggap berpotensi mendatangkan keuntungan yang besar, sehingga mengakibatkan tanaman kurang baik dan produksi rendah. Ditengah perjuangan pemerintah untuk mencapai keberhasilan pembangunan pertanian yang tangguh sebagai dasar pembangunan industri, diharapkan peran aktif dari seluruh komponen yang ada termasuk seluruh generasi muda yang terlibat langsung maupun tidak langsung dalam bidang pertanian (Anonim, 2007).

Penelitian sebelumnya telah dilakukan Siti Meiska Amelia (2018) yang melakukan penelitian berjudul Efisiensi Sistem Pemasaran Cengkeh (Syzygium Aromaticum) di Kabupaten Pesisir Barat. Berdasarkan penelitiannya pemasaran cengkeh di Kabupaten Pesisir Barat belum efisien karena: (a). Struktur pasar yang dihadapi adalah oligoposni, (b). Perilaku pasar menunjukkan bahwa petani cenderung berperan sebagai price taker, penjualan cengkeh dilakukan secara bertahap oleh petani dan (c). Keragaman pasar menunjukkan bahwa marjin pemasaran relatif tinggi dan RPM masih tinggi (93\%), walaupun producer's share yang diperoleh sudah tinggi $(96,84 \%)$.

Tabel 1. Luas Lahan Dan Produksi Cengkeh perKecamatan di Kabupaten Enrekang Tahun 2019

\begin{tabular}{rcrr}
\hline \multirow{2}{*}{ No } & \multirow{2}{*}{ Kecamatan } & \multicolumn{3}{c}{ Cengkeh } \\
\cline { 2 - 5 } & Enrekang & 68 & Produksi (ton) \\
\hline 1 & Anggeraja & 12 & 19.8 \\
2 & 562 & 2.2 \\
3 & Baraka & 377 & 121.9 \\
4 & Malua & 606 & 149.3 \\
5 & Buntu batu & 173 & 106 \\
6 & Bungin & 50 & 37 \\
7 & Alla & 1,543 & 6.2 \\
8 & Curio & 60 & 260.5 \\
9 & Baroko & 99 & 22 \\
10 & Masalle & 9 & \\
11 & Cendana & 110 & 1.3 \\
12 & Maiwa & \multicolumn{3}{c}{} \\
\hline \multicolumn{7}{c}{ Jumlah } & $\mathbf{1 . 3 2 1}$ & $\mathbf{5 8 3 , 9}$ & \\
\hline
\end{tabular}

Sumber Data : Dinas Pertanian dan Perkebunan Kab. Enrekang (2019) 
Produksi tanaman perkebunan khususnya tanaman cengkeh di tiap Kecamatan di Kabupaten Enrekang berbeda-beda, untuk Kecamatan Baraka yang merupakan salah satu Kecamatan memiliki jumlah produksi cengkeh tertinggi sebanyak 121,9 ton setelah Kecamatan Curio dengan produksi 260,5 ton yang ada di Kabupaten Enrekang (Dinas Pertanian, 2019).

Tabel 2. Perkembangan Luas Areal dan Produksi Cengkeh dalam Lima Tahun Terakhir di Kabupaten Enrekang Tahun 2019

\begin{tabular}{|c|c|c|}
\hline Tahun & \multicolumn{1}{c}{$\begin{array}{c}\text { Luas Areal } \\
(\mathrm{Ha})\end{array}$} & $\begin{array}{c}\text { Produksi } \\
\text { (Ton) }\end{array}$ \\
\hline $\mathbf{2 0 1 4}$ & 2.662 & 540 \\
\hline $\mathbf{2 0 1 5}$ & 3.285 & 540 \\
\hline $\mathbf{2 0 1 6}$ & 3.669 & 572 \\
\hline $\mathbf{2 0 1 7}$ & 3.669 & 631 \\
\hline $\mathbf{2 0 1 8}$ & 3.669 & 661 \\
\hline
\end{tabular}

Sumber Data : Dinas Pertanian dan Perkebunan Kab. Enrekang (2019)

Cengkeh di Kabupaten Enrekang merupakan sektor yang sangat menunjang pendapatan para petani itu sendiri.Perkembangan komoditi cengkeh di Kabupaten Enrekang berlangsung sesuai dengan laju luas tanaman dan

Tabel 3. Perkembangan Produksi Cengkeh dalam Lima Tahun Terakhir di Desa Langda Tahun 2019

\begin{tabular}{|c|c|c|}
\hline Tahun & $\begin{array}{c}\text { Luas Areal } \\
(\mathrm{Ha})\end{array}$ & $\begin{array}{c}\text { Produksi } \\
(\text { Ton })\end{array}$ \\
\hline $\mathbf{2 0 1 4}$ & 53 & 17 \\
\hline $\mathbf{2 0 1 5}$ & 53 & 16,6 \\
\hline $\mathbf{2 0 1 6}$ & 67 & 19,8 \\
\hline $\mathbf{2 0 1 7}$ & 64 & 23,9 \\
\hline $\mathbf{2 0 1 8}$ & 61 & 25,4 \\
\hline
\end{tabular}

Sumber Data : Balai Pelatihan Pertanian Kecamatan Buntu Batu (2019)

Desa Langda merupakan salah satu sentral penghasil cengkeh di Kecamatan Buntu Batu Kabupaten Enrekang. Ratarata masyarakat di Desa ini umumnya berprofesi sebagai petani cengkeh dengan jumlah Petani 550 Orang. Komoditi inilah yang merupakan penyambung pendapatan terbesar bagi petani yang mengusahakannya. Dengan adanya tanaman cengkeh para petani di Desa Langda mampu membiayai keluarga mereka dari penghasilan penjualan cengkeh.

Usaha pertanian cengkeh ini kebanyakan para petani menggarap tanamannya sendiri kecuali petani yang memiliki lahan yang cukup luas dimana produksi. Pada tahun 2014 luas areal panen $2.662 \mathrm{Ha}$ dengan produksi sebesar 540 ton, dan pada tahun 2018 produksi cengkeh sebesar 661 dengan luas panen 3.669 (Dinas Pertanian, 2019). 
uraian pada latar belakang diatas maka dapat disimpulkan yang menjadi perumusan masalah dalam penelitian ini yaitu bagaimana faktor internal dan eksternal yang mempengaruhi pemasaran cengkeh? dan bagaimana strategi pemasaran cengkeh produksi Desa Langda Kecamatan Buntu Batu Kabupaten Enrekang? Penelitian ini bertujuan untuk mengetahui faktor internal dan eksternal yang mempengaruhi pemasaran cengkeh dan menentukan strategi yang memungkinkan untuk diterapkan dalam pemasaran cengkeh Petani cengkeh Desa Langda Kecamatan Buntu Batu Kabupaten Enrekang.

\section{METODE PENELITIAN}

\section{Waktu dan Tempat Penelitian}

Penelitian dilaksanakan selama dua bulan pada bulan Maret sampai April 2020 di Desa Langda Kecamatan Buntu Batu Kabupaten Enrekang. Alasan penulis memilih lokasi penelitian dikarenakan di Desa Langda merupakan salah satu penghasil Cengkeh terbesar di Kecamatan Buntu Batu dan merupakan salah satu Desa yang bergerak dalam bidang Perkebunan dengan Usaha Tani budidaya Cengkeh.

\section{Populasi}

Populasi dalam penelitian ini adalah semua petani cengkeh berdasarkan Kepala Keluarga dengan jumlah 550 Orang yang berada di Desa Langda Kecamatan Buntu Batu Kabupaten Enrekang.

\section{Sampel}

Penentuan sampel yang digunakan adalah random sampling dimana dalam penentuan responden dilakukan dengan cara memilih secara acak dari Petani cengkeh dan instansi terkait sebagai sampel dalam penelitian. Menurut Arikunto (2006), apabila kurang dari 100 lebih baik diambil semuanya sehingga penilitiannya merupakan penelitian populasi, jika jumlah subjeknya besar dapat diambil antar $10-15 \%$ atau 20 $55 \%$. Responden sebanyak 55 Orang dari 550 jumlah populasi yang terletak di Desa Langda Kecamatan Buntu Batu Kabupaten Enrekang adalah jumlah keseluruhan responden dalam penelitian ini.

\section{Jenis-jenis dan Sumber Data}

Data yang diperoleh terdiri dari dua macam, yaitu data primer dan data sekunder. Data primer adalah data yang diperoleh langsung dari responden dengan wawancara dan menggunakan kuesioner sebagai alatnya. Mencatat langsung data yang bersumber dari dokumentasi setelah mengumpulkan data yang berkaitan dengan penelitian pada suatu instansi atau lembaga merupakan Data sekunder. Monografi daerah penelitian, daftar masyarakat yang menjadi responden dan data-data yang berkaitan dengan masyarakat di Desa Langda merupakan jenis-jenis data sekunder yang diambil .

\section{Metode Analisis Data}

Teknik pengumpulan data:

a. Kuesioner merupakan cara pengambilan data terhadap objek penelitian dengan beberapa faktorfaktor internal dan eksternal penelitian ditujukan kepada responden sebagai pertanyaan.

b. Observasi merupakan pengambilan data dengan cara mengamati objek penelitian untuk mendapatkan gambaran yang jelas terhadap tempat penelitian

c. Wawancara merupakan teknik pengambilan data dengan cara tanya jawab secara langsung terhadap responden dengan menggunakan kuesioner.

Matriks SWOT digunakan sebagai alternatif yang tepat untuk mengolah data. Data kuantitatif dan kualitatif yang 
diperoleh dikelola dalam tiga tahapan sebagai berikut :

1. Tahap pengumpulan input (the input stage)

2. Tahap pemanduan (the matcing stage)

3. Tahap penetapan strategi (the decision stage)
Tabel analisis IFAS dan EFAS digunakan sebagai cara identifikasi dan pengumpulan data, kemudian matriks I-E dan matriks SWOT diugunakan untuk menganalisis masalah. Berikut adalah pengolahan data yang dimasukkan kedalam Tabel 4.

Tabel 4. Matriks SWOT

\begin{tabular}{|c|c|c|}
\hline EFAS IFAS & 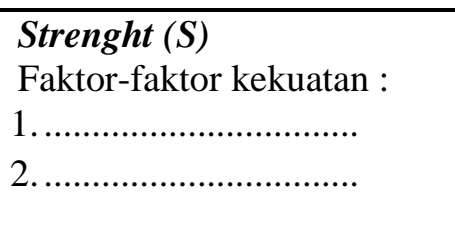 & $\begin{array}{l}\text { Weakness }(\boldsymbol{W}) \\
\text { Faktor-faktor kelemahan } \\
\text { internal : } \\
1\end{array}$ \\
\hline 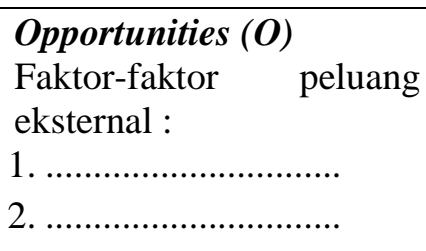 & $\begin{array}{|lr|}\text { Strategi S-O } \\
\text { Strategi pemanfaatan } \\
\text { peluang dengan } \\
\text { menggunakan keuatan }\end{array}$ & $\begin{array}{l}\text { Strategi W-O } \\
\text { Strategi pemanfaatkan } \\
\text { peluang } \\
\text { meminimalisir kelemahan }\end{array}$ \\
\hline 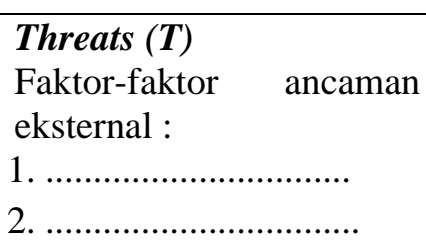 & $\begin{array}{l}\text { Strategi S-T } \\
\text { Strategi mengatasi ancaman } \\
\text { dengan menggunakan } \\
\text { peluang }\end{array}$ & $\begin{array}{lr}\text { Strategi W-T } \\
\text { Strategi menghindari } \\
\text { ancaman dengan } \\
\text { meminimalisir kelemahan }\end{array}$ \\
\hline
\end{tabular}

Sumber : Rangkuti 2010

Rangkuti (2010), berpendapat bahwa membuat matrik dengan menggabungkan SWOT menjadi suatu matriks dan kemudian diidentifikasikan semua aspek dalam SWOT. Kuadran tempat bertemunya SWOT tersebut kemudian dibuat strategi yang sesuai dengan aspekaspek SWOT. Adapun Strategi-strategi yang dimaksud di atas ada 4 strategi yaitu sebagai berikut:

1. Strategi S-O yaitu memaksimalkan potensi kekuatan untuk meraih peluang semaksimal mungkin atau menggunakan kekuatan untuk menangkap peluang.

2. Strategi S-T yaitu memaksimalkan potensi/kekuatan untuk mengurrangi seminimal mungkin ancaman yang ada.

3. Strategi W-O yaitu meminimalkan kelemahan untuk meraih peluang semaksimal mungkin atau mengatasi kelemahan dengan mengambil kesempatan.

4. Strategi W-T yaitu meminimalkan kelemahan untuk meminimalkan ancaman yang ada atau menghindarkan ancaman.

\section{Matriks Internal-Eksternal (I-E)}

Matriks IE adalah alat analisis yang digunakan untuk mengukur posisi suatu unit bisnis dalam suatu perusahaan yang disusun berdasarkan total nilai matriks IFAS dan EFAS setelah melakukan perhitungan dari semua faktor-faktor yang diteliti. Penentuan strategi yang tepat untuk diaplikasikan oleh suatu perusahaan digambarkan dalam matriks I-E dalam tampilan sembilan sel penilaian, seperti pada gambar berikut : 


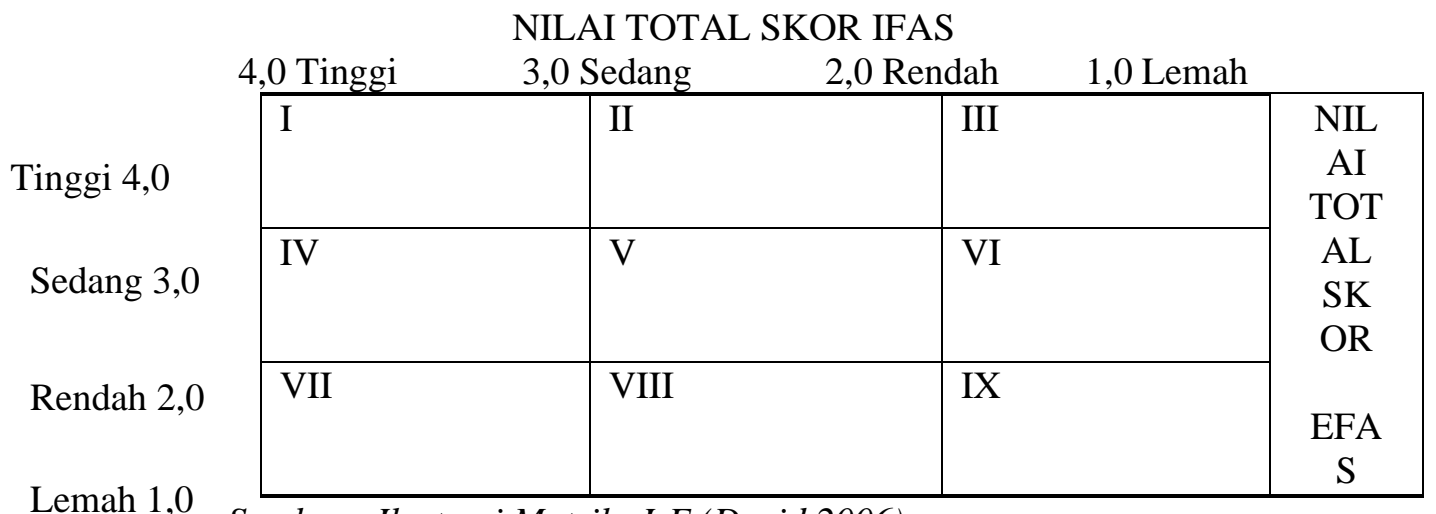

Lemah 1,0

Sumber : Ilustrasi Matriks I-E (David 2006)

Dijelaskan bahwa bagaimana posisi perusahaan setelah memperoleh total skor IFAS dan EFAS serta mengidentifikasikan sembilan sel strategi perusahaan dalam matriks I-E, tetapi pada prinsipnya kesembilan sel itu dapat dikelompokkan menjadi strategi utama yaitu:

1. Strategi tumbuh dan bina (growth and build), yang berada pada sel I, II, dan IV. Strategi yang tepat untuk diterapkan adalah strategi intensif (penetrasi pasar, peningkatan pasar dan peningkatan produk) atau strategi integrative (integrasi ke depan, ke belakang dan horizontal).

2. Strategi mempertahankan dan memelihara (hold and maintain), yang berada pada sel III, V dan VII. Strategi penetrasi pasar dan peningkatan produk adalah dua strategi yang terbanyak dilakukan untuk jenis-jenis divisi ini.

3. Strategi panen atau divestasi (harvest or divest), yang berada pada sel VI, VIII, dan IX. Strategi yang umum dipakai adalah strategi pengurangan modal dan strategi pembubaran perusahaan.

Kesuksesan suatu perusahaan digambarkan dalam matrik I-E disekitar posisi sel I. Nilai-nilai IFAS dikelompokkan kuat apabila berada pada nilai $(3,0-4,0)$, sedang $(2,0-2,99)$, dan lemah $(1,0-1,99)$. Sedangkan nilai-nilai EFAS dapat dikelompokkan tinggi apabila berada pada kisaran nilai $(3,0$ $4,0)$, sedang $(2,0-2,99)$ dan rendah $(1,0-$ 1,99) (Wijayanti,2009).

Selanjutnya pada tahapan ini rekomendsi strategi yang diperoleh adalah strategi tumbuh dan bina (growth and build).

\section{HASIL DAN PEMBAHASAN}

Strategi pemasaran petani Desa Langda pada tahap produksi hanya sampai pada pengeringan kemudian disimpan, harga menyesuikan dengan harga pasar karena mayoritas petani menjual produksi setelah ada kebutuhan tertentu, kemudian promosi yang dilakukan ada dua metode yaitu menghubungi langsung pedagang pengumpul dan membawa hasil produksi ke pasar minguan, kemudian penjualan dilakukan di rumah dan pasar mingguan terdekat.

Identifikasi faktor internal dilakukan untuk mengetahui kekuatan dan kelemahan pemasaran cengkeh produksi Desa Langda Kecamatan Buntu Batu Kabupaten Enrekang. Sejumlah kekuatan dan kelemahan dari hasil analisis yang dilakukan oleh penulis, secara ringkas dapat dilihat pada Tabel 5 . 
Tabel 5. Faktor-Faktor Internal

Kekuatan

1. Produksi tinggi

2. Budidaya mudah

3. Lokasi perkebunan mudah terjangkau

4. Produksi tahan lama untuk disimpan

5. Bisa tumbuh dengan pola tanam tumpangsari

\section{Kelemahan}

1. Kurangnya pemahaman tentang rantai pasar

2. Tidak ada pengolahan pascapanen

3. Kurangnya penggunaan teknologi

4. Kurangnya promosi produksi

5. Proses budidaya tanaman sampai berbuah terbilang lama

Identifikasi faktor eksternal dilakukan untuk mengetahui peluang dan ancaman yang dihadapi Petani cengkeh di yang berada di Desa Langda Kecamatan Buntu
Kabupaten Enrekang. Berdasarkan hal tersebut, maka peluang dan ancaman yang dihadapi Petani cengkeh pada tempat tersebut, dapat dilihat pada Tabel 6.

Tabel 6. Faktor-Faktor Eksternal

Peluang

a. Akses jalan mudah

b. Dukungan pemerintah

c. Pemasaran yang fleksibel

d. Tingginya permintaan pasar

e. Pemasaran digital

Ancaman

1. Cuaca buruk

2. Persaingan komoditi yang sama

3. Harga cengkeh yang tidak stabil

4. Regulasi pemerintah

5. Pedagang calo

\section{Sumber: Data Primer Setelah Diolah (2020)}

\section{Pemberian Bobot dan Peringkat}

Penentuan bobot merupakan hasil dari penjumlahan skor setiap indikator dibagi jumlah keseluruhan skor indikator dengan menggunakan tabel hipotesa yang terdiri dari 3 tingkatan skala penilaian untuk menentukan skor perbandingan anatara S-W (IFAS) dan O-T (IFAS) pada setiap kolom dengan masing-masing IFAS dan EFAS memiliki bobot 1,00 . Penentuan rating merupakan hasil dari penjumlahan skor setiap indikator pada IFAS dan EFAS dalam bentuk kuesioner dibagi jumlah keseluruhan responden.

Rata-rata dari faktor internal dan eksternal yang diperoleh atas pendapat responden/petani yang ada di Desa Langda Kecamatan Buntu Batu Kabupaten Enrekang dapat dilihat pada Tabel 7. 
Tabel 7. Internal Strategic Factors Analysis Summary (IFAS)

\begin{tabular}{|c|c|c|c|c|c|}
\hline Faktor internal & & bobot & atin & skor & \\
\hline kekuatan & & & & & \\
\hline 1. Produksi tinggi & & $\overline{0,13}$ & 3 & & 0,39 \\
\hline 2. Budidaya mudah & 0,12 & 4 & & 0,48 & \\
\hline 3. Lokasi perkebunan mudah terjangkau & 0,11 & 4 & & 0,44 & \\
\hline 4. Produksi tahan lama untuk disimpan & & 0,09 & 4 & & 0,36 \\
\hline $\begin{array}{l}\text { 5. Bisa tumbuh dengan pola tanam } \\
\text { tumpangsari }\end{array}$ & 0,09 & 4 & & 0,36 & \\
\hline
\end{tabular}

\begin{tabular}{llllll}
\hline Total & & 0,54 & & 2,03 \\
\hline kelemahan & & & & \\
\hline $\begin{array}{l}\text { 1. Kurangnya pemahaman tentang } \\
\text { rantai pasar }\end{array}$ & 0,14 & 1 & 0,14 & \\
2. Tidak ada pengolahan pascapanen & 0,11 & 1 & & 0,11 & \\
3. Kurangnya penggunaan teknologi & 0,10 & 1 & & 0,10 & \\
4. Kurangnya promosi produksi & & 0,06 & 1 & & 0,06 \\
5. Proses budidaya sampai berbuah & 0,05 & 2 & & 0,10 & \\
$\quad$ terbilang lama & & & & & \\
Total & & 0,46 & & 0,51 & \\
\hline Total IFAS & & $\mathbf{1 , 0 0}$ & & & $\mathbf{2 , 5 4}$ \\
\hline
\end{tabular}

Sumber : Data Primer Setelah Diolah (2020)

Tabel tersebut menunjukkan bahwa hasil perhitungan dari Internal Strategic Factors Analysis Summary (IFAS) memiliki bobot sebesar 2,54. Bobot tersebut menunjukan bahwa tingkat keberhasilan petani dalam kegiatan usaha taninya ada pada level standar/sedang, karena kemampuan petani untuk meminimalisir kelemahan usaha tani dengan memanfaatkan kekuatan tergolong sedang. Hal ini berdasar pada pendapat Wijayanti (2009) yang menyatakan bahwa jika total skor IFAS $(3,0-4,0)$ berarti kondisi internal perusahaan tinggi/kuat, jika $(2,0-2,99)$ berarti kondisi internal suatu perusahaan rata-rata/sedang dan jika $(1,0-1,99)$ berarti kondisi internal perusahaan rendah/lemah. Kekuatan terbesar dan paling berpengaruh dalam produksi cengkeh ini adalah budidaya mudah dengan skor 0,48 sedangkan kelemahan utama dalam strategi pemasaran cengkeh adalah kurangnya pemahaman tentang rantai pasar dengan skor 0,14 sehingga mempengaruhi keuntungan yang diraut petani. 
Tabel 8. External Strategic Factors Analysis Summary (EFAS)

\begin{tabular}{|c|c|c|c|c|c|}
\hline EAKTOR EKSTERNAL & & OBOT & & ATING & KOR \\
\hline PELUANG & & & & & \\
\hline 1. Pemasaran digital & 0,09 & & 3 & 0,27 & \\
\hline 2. Akses jalan mudah & 0.14 & & 3 & 0,42 & \\
\hline 3. Dukungan pemerintah & & 0,12 & & 3 & 0,36 \\
\hline 4. Pemasaran yang fleksibel & 0,12 & & 4 & 0,48 & \\
\hline 5. Tingginya permintaan pasar & & 0,12 & & 3 & 0,36 \\
\hline Total & & 0,59 & & & 1,89 \\
\hline$\overline{\text { ANCAMAN }}$ & & & & & \\
\hline 1. Regulasi pemerintah & & 0,05 & & 1 & 0,05 \\
\hline 2. Harga cengkeh yang tidak stabil & & 0,11 & & 2 & 0,22 \\
\hline 3. Cuaca buruk & & 0,11 & & 1 & 0,11 \\
\hline 4. Persaingan komoditi yang sama & 0,06 & & 2 & 0,12 & \\
\hline 5. Pedagang calo & & 0,08 & & 1 & 0,08 \\
\hline Total & & 0,41 & & & 0,58 \\
\hline$\overline{\text { TOTAL EFAS }}$ & 1,00 & & & 2,47 & \\
\hline
\end{tabular}

Sumber : Data Primer Setelah Diolah (2020)

Tabel tersebut menunjukkan bahwa hasil analisis External Strategic Factors Analysis Summary (EFAS) memiliki jumlah total skor 2,47. Hasil perhitungan ini menunjukkan bahwa kemampuan petani dalam memanfaatkan peluang dan mengatasi ancaman untuk memproduksi cengkeh tergolong sedang. Pernyataan tersebut berdasar pada pendapat Wijayanti (2009) yang mengatakan bahwa jika jumlah total skor berada pada kisaran $(3,0-$ 4,0 ) berarti perusahaan merespon kuat terhadap peluang dan ancaman yang mempengaruhi perusahaan, jika $(2,0-2,99)$ berarti perusahaan merespon sedang terhadap peluang dan ancaman yang ada dan jika $(1,0-1,99)$ berarti perusahaan tidak dapat merespon peluang dan ancaman yang ada. Peluang terbesar dan paling berpengaruh dalam produksi cengkeh adalah pemasaran yang fleksibel dengan skor 0,48. Sedangkan ancaman utama dalam produksi cengkeh adalah harga cengkeh yang tidak stabil dengan skor 0,22 yang mengakibatkan pendapatan petani sedikit/rugi, hal ini disebabkan karena harga cengkeh yang tidak stabil dan kurangnya pemahan tentang rantai pasar sehingga berpengaruh pada pendapatan petani.

Hasil analisis dengan berdasar pada tabel IFAS dan EFAS menunjukkan bahwa ratarata skor IFAS adalah 2,54, jumlah skor tersebut menggambarkan kondisi internal usahatani cengkeh tergolong sedang. Sedangkan tabel EFAS menunjukkan bahwa rata-rata jumlah skor adalah 2,47, skor tersebut menggambarkan bahwa kondisi eksternal usahatani cengkeh juga tergolong sedang. Berikut ini adalah total nilai yang di bobot pada tabel IFAS dan EFAS yang akan disusun pada matriks Internal-External (IE), Kemudian akan dirumuskan strategi pemasaran cengkeh di Desa Langda Kecamatan Buntu Batu Kabupaten Enrekang yang sesuai dengan posisi produksi cengkeh, seperti pada gambar berikut : 
NILAI TOTAL SKOR IFAS
4,0 Tinggi
3,0 Sedang
2,0 Rendah
1,0 Lemah

\begin{tabular}{|c|c|c|c|c|}
\hline Tinggi 4,0 & I & II & III & $\begin{array}{c}\text { NIL } \\
\text { AI } \\
\text { TOT }\end{array}$ \\
\hline Sedang 3,0 & IV & $\begin{array}{l}\mathrm{V} 2.54 \\
2.47\end{array}$ & VI & $\begin{array}{l}\text { AL } \\
\text { SK } \\
\text { OR }\end{array}$ \\
\hline Rendah 2,0 & VII & VIII & IX & $\begin{array}{c}\text { EFA } \\
\mathrm{S} \\
\end{array}$ \\
\hline
\end{tabular}

Gambar diatas menunjukkan bahwa posisi produksi cengkeh di Desa Langda berada pada masing-masing kotak sel IV dengan skor 2,54 dan 2,47. Total skor yang dihitung menggunakan matriks IFAS dan EFAS menggambarkan kondisi internal usahatani cengkeh di Desa Langda Kecamatan Buntu Batu Kabupaten Enrekang tergolong sedang, yang perlu dipelihara dan dipertahankan, kondisi ini dengan menggunakan alat ukur matriks I-E menunjukkan hasil bahwa petani merespon sedang.

\section{Alternatif Strategi}

1. Strategi S-O yaitu memaksimalkan potensi kekuatan untuk meraih peluang semaksimal mungkin atau menggunakan kekuatan untuk menangkap peluang.

2. Strategi S-T yaitu memaksimalkan potensi/kekuatan untuk mengurrangi seminimal mungkin ancaman yang ada.

3. Strategi W-O yaitu meminimalkan kelemahan untuk meraih peluang semaksimal mungkin atau mengatasi kelemahan dengan mengambil kesempatan.

4. Strategi W-T yaitu meminimalkan kelemahan untuk meminimalkan ancaman yang ada atau menghindarkan ancaman.

Berikut ini akan dikemukakan alternatif strategi pemasaran cengkeh yang disajikan pada matriks SWOT 


\begin{tabular}{|c|c|c|}
\hline EFAS & $\begin{array}{l}\text { Kekuatan/Strenght }(\boldsymbol{S}) \\
\text { 1. Produksi tinggi } \\
\text { 2. Budidaya mudah } \\
\text { 3. Lokasi perkebunan } \\
\text { mudah terjangkau } \\
\text { 4. Produksi tahan lama } \\
\text { untuk disimpan } \\
\text { 5. Bisa tumbuh dengan } \\
\text { pola tanam tumpangsari }\end{array}$ & \begin{tabular}{|lll}
\multicolumn{3}{|c}{ Kelemahan/Weakness $(\boldsymbol{W})$} \\
1. & Kurangnya pemahaman \\
& tentang rantai pasar \\
2. & Tidak ada pengolahan \\
& pascapanen \\
3. & Kurangnya penggunaan \\
& teknologi \\
4. & Kurangnya promosi produksi \\
5. & Proses budidaya tanaman \\
& sampai berbuah terbilang \\
& lama
\end{tabular} \\
\hline $\begin{array}{l}\text { Peluang/Opportunities } \\
\text { (O) } \\
\text { 1. Pemasaran digital } \\
\text { 2. Akses jalan mudah } \\
\text { 3. Dukungan pemerintah } \\
\text { 4. Pemasaran yang } \\
\quad \text { fleksibel } \\
\text { 5. Tingginya permintaan } \\
\quad \text { pasar }\end{array}$ & $\begin{aligned} & \text { 1. } \text { Menggunakan metode } \\
& \text { pemasaran berbasis } \\
& \text { online (S1-O1) } \\
& \text { 2. } \text { Memperluas lapangan } \\
& \text { kerja atau lahan } \\
& \text { pertanian (S2-O2) } \text { Meningkatkan } \\
& \text { 3. } \text { kerjasama dengan } \\
& \text { pemerintah (S3-O3) } \\
& \text { 4. } \\
& \text { Meningkatkan nilai } \\
& \text { jual produksi (S4-O4) } \\
& \text { 5. } \\
& \text { Meningkatkan kualitas } \\
& \text { produksi (S5-O5) }\end{aligned}$ &  \\
\hline $\begin{array}{l}\text { AncamanThreats }(\boldsymbol{T}) \\
\text { 1. Regulasi pemerintah } \\
\text { 2. Harga cengkeh yang } \\
\text { tidak stabil } \\
\text { 3. Cuaca buruk } \\
\text { 4. Pedagang calo } \\
\text { 5. Persaingan komoditi } \\
\text { yang sama }\end{array}$ & 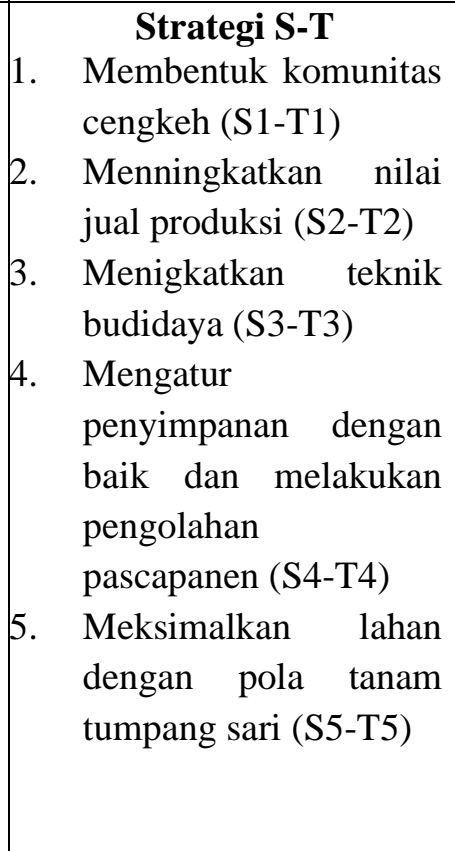 & 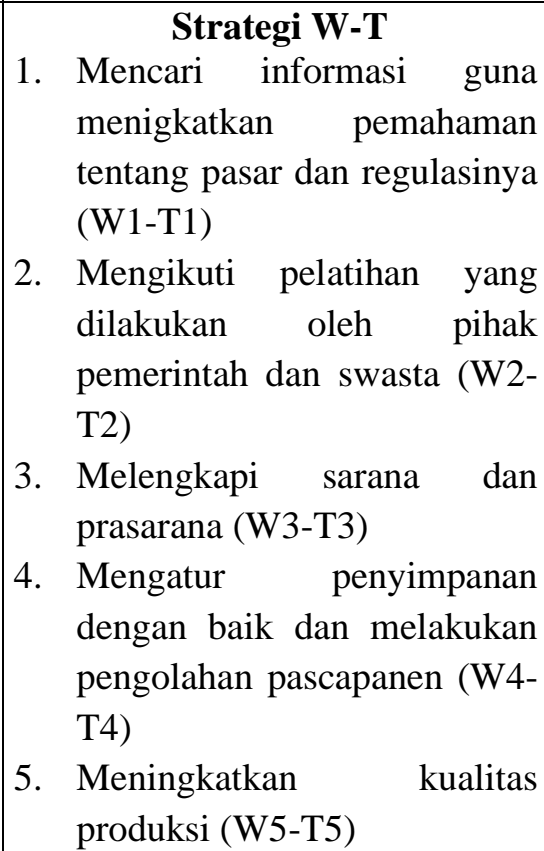 \\
\hline
\end{tabular}

Sumber. Data Primer Setelah Diolah (2020) 


\section{Penetapan Keputusan}

Pengambilan keputusan merupakan metode salanjutnya dengan menggunakan rumus matriks SWOT sebagai alat ukur analisis kuantitatif pada masing-masing jumlah nilai skor $\mathrm{S}-\mathrm{O}$, W-O, S-T dan W-T. Perumusan strategi dapat dilihat pada gambar matriks IFAS dan EFAS sebagai berikut :

\begin{tabular}{|l|c|c|}
\hline EFAS & Strenght (S) & Weakness (W) \\
\hline Opportunities (O) & $\begin{array}{c}\text { Strategi SO } \\
2,03+1,89=3,92\end{array}$ & $\begin{array}{c}\text { Strategi WO } \\
\mathbf{0 , 5 1 + 1 , 8 9 = 2 , 4 0}\end{array}$ \\
\hline THREATS (T) & $\begin{array}{c}\text { Strategi st } \\
\mathbf{2 , 0 3 + 0 , 5 8}=\mathbf{2 , 6 1}\end{array}$ & $\begin{array}{c}\text { Strategi WT } \\
\mathbf{0 , 5 1 + 0 , 5 8}=\mathbf{1 , 0 9}\end{array}$ \\
\hline
\end{tabular}

Sumber : Data Primer Setelah Diolah (2020)

Gambar 6. Penjumlahan Skor Matriks IFAS dan EFAS

Gambar 6 menunjukkan bahwa strategi S-O merupakan strategi yang dapat digunakan karena memiliki nilai tertinggi dari kesuluruhan strategi yang ada, dengan nilai skor 3,92. Hsil tersebut dapat disimpulkan bahwa strategi S-O yang tepat untuk Desa Langda Kecamatan Buntu Kabupaten Enrekang adalah sebagai berikut :

1. Menggunakan metode pemasaran berbasis online

Pemasaran berbasis online merupakan suatu metode yang digunakan untuk memanfaatkan alat teknologi dalam bertataniaga yang berfungsi untuk memperluas pangsa pasar dan mempromosikan produksi. Selain mudah dan terjangkau metode ini sudah menjadi kebutuhan pokok bagi setiap pelaku tataniaga, untuk menghadapi pemasaran global yang hampir setiap waktu memiliki perubahan sistem yang moderen karena alat teknologi semakin canggih atau yang kita kenal dengan istilah revolusi industri.

2. Memperluas lapangan kerja atau lahan pertanian

Memperluas lapangan kerja merupakan salah satu metode yang strategis dalam kegiatan usaha tani ini untuk meningkatkan produksi. Selain karena tanaman cengkeh mudah dibudiya, kondisi geografis perkebunan para petani juga sangat mendukung dengan akses jalan yang mudah terjangkau.

3. Meningkatkan kerjasama dengan pemerintah

Pemerintah dan Petani merupakan satu kesatuan yang tidak bisa dipisah dalam sebuah kegiatan usaha karena keduanya memiliki fungsi yang saling melengkapi satu sama lain. Dengan meningkatkan kerjasama petani akan mudah menjalankan kegiatan usaha melalu regulasi pemerintah yang sesuai dengan kebutuhan petani seperti bantuan sarana produksi, mengontrol harga produk, pelatihan yang konstruktif dan lain-lain.

4. Meningkatkan nilai jual produksi

Strategi ini merupakan salah satu metode yang menjadi buah dari kerjasama antara pemerintah dan petani melalui pelatihan seperti pengolahan pascapanen, untuk memanfaatkan bahan baku yang dapat disimpan lama dan pemasaran yang fleksibel dalam upaya meningkatkan pendapatan.

5. Meningkatkan kualitas produksi 
Produksi yang dimaksud di sini adalah produk cengkeh kering, dimana pengelolaan mulai dari sarana dan prasarana sampai pada pengeringan akan menentukan kualitas produk cengkeh kering dan nilai jualnya, sedangkan sebagian besar petani di Desa Langda menerapkan teknik budidaya yang masih tergolong sederhana karena sarana dan prasarana yang tidak memadai sehingga kualitas produksi masih tergolong kuarang efektif. Dalam upaya meningkatkan kualitas produksi untuk memanfaatkan pola tanam tumpang sari dengan memaksimalkan permintaan pasar yang tinggi maka petani harus menerapkan metode yang strategis yaitu melengkapi sarana prasarana dan menjalin kerjasama dengan pihak pemerintah.

\section{SIMPULAN}

\section{Kesimpulan}

Hasil penelitian mengenai Strategi Pemasaran Cengkeh (Syzgium Aromaticum) Produksi Desa Langda Kecamatan Buntu Batu Kabupaten Enrekang, dapat disimpulkan bahwa penentuan strategi yang tepat dari hasil analisis SWOT berdasarkan matriks kuadran SWOT adalah Strategi SO (Strenghts-opportunities) yaitu sebagai berikut: a) Menggunakan metode pemasaran berbasis online. b) Memperluas lapangan kerja atau lahan pertanian. c) Meningkatkan kerjasaam dengan pemerintah. d) Meningkatkan nilai jual produksi. e) Meningkatkan kualitas produksi.

\section{Saran}

Peneliti menyarankan kepada pihak terkait dalam penelitian ini sebagai berikut :

1. Dukungan pemerintah sangat diperlukan untuk meningkatkan kesejahteraan petani cengkeh dengan memfasilitasi sarana dan prasaran produksi, melakukan pelatihan tentang penggunaan teknologi dan meningkatkan kerjasama dengan petani dalam pengoptimalan pemasaran untuk meningkatkan pendapatan petani.

2. Responden diharapkan berinovasi untuk mebuat pengolahan produksi pascapanen guna meningkatkan pendapatan sekaligus meminimalisir kerugian.

\section{DAFTAR PUSTAKA}

Amelia.S.M, 2018. "Efisiensi Sistem Pemasaran Cengkeh (Syzygium Aromaticum) di Kabupaten Pesisir Barat. Skripsi Fakultas Pertanian Universitas Lampung Bandar Lampung.

Arikunto S, 2006. "Metodologi Penelitian". Yogyakarta. Bina Aksara

David, Fred R, 2006. Manajemen Strategi. Buku 1, Edisi Kesepuluh. Jakarta: Salemba Empat.

Dinas Pertanian dan Perkebunan Kabupaten Enrekang Tahun 2018.Enrekang dalam angka 2018. Enrekang.

Djanna.N, 2007. Divertifikasi Penggunaan Cengkeh, Bogor: Balai Besar Penelitian dan Pengembangan Pasca Panen Pertanian Indonesian Center For Agricultural Postharvest Research and Develoment.

Anonim, 2019. "Profil Desa Langda Kecamatan Buntu Batu Kabupaten Enrekang”. Desa Langda Kecamatan Buntu Batu Kabupaten Enrekang.

Rangkuti 2010. Matriks SWOT Teknik Membedah Kasus Bisnis. Gramedia Puataka Utama. Jakarta.

Siregar.A.R, 2011. "Analisis Disparitas Harga dan Potensi Persaingan tidak Sehat pada Distribusi Cengkeh" Jurnal Agribisnis Vol 10 No.3: 32-24

Wijayanti, R. 2009. Strategi Peng embangan 
Usaha Sayuran Organik.

Skripsi Program Studi

Departement Agribisnis.

Fakultas Ekonomi dan

Manajement IPB Bogor. 